\title{
NUMERICAL SIMULATION OF SINTER PROCESS AND PELLETIZING PROCESS*
}

\author{
Bernhard Hieb/ ${ }^{1}$ \\ Johann Reidetschlaeger ${ }^{2}$ \\ Edmund Fehringer ${ }^{3}$
}

\begin{abstract}
Global trends that are constantly challenging the iron and steel producers are related to worsening of the iron ore grades, higher substitution rates of main iron ores to cheaper raw materials due to economic pressure and increased environmental standards. Changing the raw materials in an operating plant can significantly influence the sintering or pelletizing process. Adjusting all process parameters to regain stable and high productive operation takes considerable time and causes production losses. Furthermore changes in raw materials lead to variations in the process gas flows and emission concentrations. Therefore SVAI developed two models for numerical simulation of sintering process and pelletizing process. Amongst others the models are based on Ergun equation and include chemical reactions of the related process. For already operating plants the simulations shall predict changes of the process parameters when raw materials are exchanged or when operational parameters are varied. Furthermore the simulations give advantageous information for the design of green field plants and allow the simulation of different plant configurations. The objective of this paper is to demonstrate what the latest developments are in these numerical simulations and what Siemens VAl is doing to overcome the remaining challenges in this field.
\end{abstract}

Keywords: Numerical simulation; Sinter process; Pelletizing process; Agglomeration process; Iron ore.

1 Dipl.-Ing, Technology Expert Pelletizing, MT IR AG, Siemens VAl Metals Technologies GmbH, Linz Austria.

2 Dr., Technology Expert Sintering, MT IR AG, Siemens VAl Metals Technologies GmbH, Linz Austria

3 Dipl.-Ing, Technology Expert Sintering, MT IR AG, Siemens VAI Metals Technologies GmbH, Linz Austria.

\footnotetext{
* Technical contribution to the 44 Ironmaking and Raw Materials Seminar, $15^{\text {td }}$ Brazilian Symposium on Iron Ore and $2^{\text {nd }}$ Brazilian Symposium on Agglomeration of Iron Ore, September $15^{\text {th }}$ to $18^{\text {th }}$, 2014, Belo Horizonte, MG, Brazil.
} 


\section{INTRODUCTION}

Sinter and pellets are the main raw materials for the blast furnace. For high productivity and high energy efficiency, blast furnace operation requires a stable composition of raw materials. The burden material has to meet special criteria: it should be rich in iron content and easily reducible, and it should have a regular, close-grained structure with sufficient mechanical strength for fluidic conditions.

Sintering is a binding mechanism in which different raw materials are melted together in an agglomeration process. The particles are enlarged and they take on the desired properties for the blast furnace in question. The raw materials used in the sintering process can vary widely: different kinds of iron ores, fluxes like limestone and dolomite, and iron carriers like steel plant revert materials, dust and coke breeze. For sinter feed, the used iron ores normally vary according to the mining area and mineral composition.

The sintering process starts with the charging of a raw material mixture in to the sinter machine (Figure 1). The material is then moved on a traveling grate with a specific speed necessary for producing sinter. Shortly after charging, the ignition furnace (Figure 2) ignites the coke in the mixture. Coke produces the necessary heat of about $1400^{\circ} \mathrm{C}$ to create melted fine surfaces and produce the agglomerated burden material. After ignition, the hot zone is sucked through the bed mixture and burns from top to bottom. The burning is driven downwards by an under-pressure applied from below with a suction blower. The time required for the burning process to reach the bottom of the pallet car is called the burn-through time. Ideally, burning is over by the time the pallet car reaches the end of the sinter machine. Today's sophisticated control systems optimize the burn-through time, which depends on several parameters, such as:

- chemical composition of the sinter mixture (coke, moisture and additive content)

- pressure difference between top and bottom

- porosity of the sintering material

At the end of the sinter machine, the material is crushed, dumped onto a cooler, and after cooling screened to yield blast furnace feed (Figure 3). Undersized material from the process is recycled. The sinter product has a porous, cellular structure, and its mineralogy can be substantially different from that of the original, iron-bearing fines. With the drastically increased surface area, the reaction rate in the blast furnace is increased.

Iron ores with a higher amount of moisture, hydrates and carbonic acid are sometimes sintered to free volatiles and enrich iron concentration in the burden material. Iron ore that is hard to reduce or tends to break up or gain volume with reduction in the furnace can be transformed to a strengthened and better reducible burden material through sintering. In rare cases, sintering is used to get rid of unwanted substances in the iron ore, such as sulfur. Fine return material from different processes in the iron- and steelmaking industry can be included in the sintering process. By incorporating additional substances needed in the blast furnace, the sintering process is also used as thermal preparation for blast furnace processes. Basically, any number of raw material combinations are possible. When changing the raw material mix fed into a sintering plant, fundamental decisions have to be made. Ideally designers, engineers and operators are supported with comprehensive mathematical tools.

\footnotetext{
* Technical contribution to the $44^{\text {th }}$ Ironmaking and Raw Materials Seminar, $15^{\text {rd }}$ Brazilian Symposium on Iron Ore and $2^{\text {nd }}$ Brazilian Symposium on Agglomeration of Iron Ore, September $15^{\text {th }}$ to $18^{\text {th }}$, 2014, Belo Horizonte, MG, Brazil.
} 
Sintering of iron ore is a complex process involving numerous physical and chemical phenomena. Large transport delays and substantial recycle streams are inherent to the operation of sinter plants, making them difficult to control. Production rates and product quality are also hard to predict. Furthermore, the characteristics of available iron ores, concentrates or pellet feed and the required sinter product change over time. So although sintering is a well-established process, there is still potential for improvement in regard to efficiency and flexibility. Sinter machine performance and output quality are of key importance.

For the sintering process, the overall goal is to produce sinter at a prescribed quality (i.e. mechanical strength and reducibility) and production rate at the lowest possible cost. Given the required feed and operating parameters, the desired simulation model should be able to predict the following values at every point in the sinter bed:

- solid (liquid) material temperature

- solid (liquid) material composition

- gas temperature

- gas composition

- gas pressure

- bed shrinkage

The essential simulation components are models for the most important processes in the sintering bed, such as:

- the fluidic behavior of the gas mixture inside the sintering bed

- heat conduction transfer due to convection and diffusion in the gas and solid phase

- vaporization and condensation of water including the effects on bed voidage

- thermal decomposition of carbonates inside the bed

- coke combustion including the effect on bed voidage

- conversion of gas components (homogeneously and heterogeneously catalyzed)

- partial melt-up and solidifying of solid material mixtures including the effects on bed voidage

- shrinkage of the packed bed

- off-gas recirculation

Mathematical modeling complements and extends the knowledge that has been gained from laboratory experiments and from plant operation. The goal of the sinter simulation model is on the one hand to give the engineer the possibility of optimizing the design of the sintering process, and on the other hand to provide quick assistance for difficult process questions and decisions. The model can provide information from detailed investigations on material distribution, temperature distribution, the effect of off-gas recirculation, sulfur adsorption, heat recovery and selected wind box design.

To make the calculations feasible, the following simplifications and assumptions on the sinter process are made:

- The sinter machine is operating in a steady state, i.e. the state variables at each point in space are time invariant.

- There is no variation of solid or gas feed properties across the width of the bed.

\footnotetext{
* Technical contribution to the $44^{\text {th }}$ Ironmaking and Raw Materials Seminar, $15^{\text {rd }}$ Brazilian Symposium on Iron Ore and $2^{\text {nd }}$ Brazilian Symposium on Agglomeration of Iron Ore, September $15^{\text {th }}$ to $18^{\text {th }}$, 2014, Belo Horizonte, MG, Brazil.
} 
- There is no heat or mass transfer from the sides of the bed or in a lateral direction within the bed, so that all state variables are invariant in the lateral coordinate throughout the bed.

- As a result of the last two assumptions, the sintering bed can be modeled in two dimensions.

The main advantage of this model compared to previous attempts is the simulation of the full 2-D domain instead of a 1-D cell model. In essence, the model consists of a set of partial differential equations that describe, at every point of the calculation domain, the mass transfer of solid and gaseous components through the packed bed, heat transfer through the solid and gaseous phases, and physical processes and chemical reactions inside the bed. The following sections describe each of these processes. The model leads to a set of non-linear, coupled partial differential equations. A special numerical technique is employed to solve these equations.

\section{MATERIAL AND METHODS}

\subsection{Solid Phase Model}

The following compounds are considered:

- Ore mixture, mainly composed of Iron oxides like hematite $\left(\mathrm{Fe}_{2} \mathrm{O}_{3}\right)$, magnetite $\left(\mathrm{Fe}_{3} \mathrm{O}_{4}\right)$, wüstite $(\mathrm{FeO})$, iron carbonate $\left(\mathrm{FeCO}_{3}\right)$, calcium carbonate $\left(\mathrm{CaCO}_{3}\right)$, magnesium carbonate $\left(\mathrm{MgCO}_{3}\right)$, manganese carbonate $\left(\mathrm{MnCO}_{3}\right)$ and silicon dioxide $\left(\mathrm{SiO}_{2}\right)$

- Limestone $\left(\mathrm{CaCO}_{3}\right)$ and dolomite $\left.\left(\mathrm{CaMg} \mathrm{CO}_{3}\right]_{2}\right)$

- Calcium oxide, or quicklime $(\mathrm{CaO})$

- Hydrated lime $\left(\mathrm{Ca}(\mathrm{OH})_{2}\right)$

- Bed moisture $\left(\mathrm{H}_{2} \mathrm{O}\right)$

- Coke (C, O, H, S, ash)

Basically, any material can be added with the appropriate chemical composition.

Gas phase model

The gas phase is characterized by temperature, rate of mass flow, pressure, composition and viscosity, all of which vary with position in the sinter bed. The viscosity in turn depends on the composition and temperature of the gas, which is assumed to obey the ideal gas law. Air, possibly mixed with recycled gas, enters the sinter strand on the top of the bed; the gas is then sucked through the charge material by wind boxes placed below the grate.

The simulation considers the following gaseous components: oxygen $\left(\mathrm{O}_{2}\right)$, carbon monoxide $(\mathrm{CO})$, carbon dioxide $\left(\mathrm{CO}_{2}\right)$, water vapor $\left(\mathrm{H}_{2} \mathrm{O}\right)$, sulfur dioxide $\left(\mathrm{SO}_{2}\right)$ and nitrogen $\left(\mathrm{N}_{2}\right)$.

The following major physical processes are taken into account:

\subsection{Solid Flow}

The flow of the solid materials is determined by the velocity of the sinter belt, which moves horizontally with the moving grate at a constant speed. The sinter bed is also subject to vertical compression as a consequence of the shrinking that comes with the melting of ore. Transport equations for the single chemical compounds are used.

\footnotetext{
* Technical contribution to the $44^{\text {th }}$ Ironmaking and Raw Materials Seminar, $15^{\text {rd }}$ Brazilian Symposium on Iron Ore and $2^{\text {nd }}$ Brazilian Symposium on Agglomeration of Iron Ore, September $15^{\text {th }}$ to $18^{\text {th }}$, 2014, Belo Horizonte, MG, Brazil.
} 


\subsection{Gas Flow}

Gas enters on the top of the bed with a vertical initial velocity and moves through the bed driven by a pressure drop across the bed as a result of wind boxes positioned beneath the grating. The pressure drop across the sintering bed is a decisive factor for the amount of gas streaming through the bed and has a major influence on heat front propagation through the bed. It is thus vital to apply a suitable model for the gas flow through the packed bed of porous sinter mix. To complement the mass balance equation for the gaseous phase, the well-known empirical Ergun relation is used.

\subsection{Heat Flow}

Heat flow inside the sinter bed consists of heat convection, heat conduction, heat transfer between solid and gas phase, and heat flow due to radiation. Heat produced by chemical reactions and energy flow as a result of phase changes, i.e. melting and solidifying of solid material or vaporization and condensation, have to be added to the total heat balance for the solid and gas phases in the sinter bed.

Therefore, the partial differential equations for the temperatures of the solid and gaseous phases are calculated.

\subsection{Vaporization and Condensation}

At the beginning of the sintering process, hot off-gas from the gas burner streams through the packed bed. After the ignition period, ambient air is sucked in and heated in the burning zone of the bed. This hot gas then heats the cold sinter mix material to a certain temperature. The heat vaporizes the moisture contained in its particles.

As long as water is present in the sinter mix, the bed temperature cannot exceed the vaporization temperature.

Condensation takes place in the lower regions of the bed where the gas stream is cooled down again so that steam condensation forms on the particles.

When $\mathrm{CaO}$ is present in the sinter mix, condensed water immediately reacts to $\mathrm{Ca}(\mathrm{OH})_{2}$, and not to liquid water. Therefore, $\mathrm{CaO}$ concentration is considered as a catalyzer for condensation.

Condensed water increases the humidity of the particles. It is known that particles in the bed can only hold a certain amount of water until this part of bed is "overmoistured," that is, the pressure drop in this area increases dramatically and nearly no gas can be sucked through the bed anymore. This effect is included in the model: condensed water that cannot be held by particles anymore correspondingly decreases the void fraction of the bed at this point.

\subsection{Melting and solidification}

During the process of melting iron-bearing materials, the bed shrinks. This bed shrinkage is an additional factor that needs to be taken into account in the sinter model. The major shrinkage effect is assumed to be hot slump, though shrinkage or expansion can be caused by phenomena such as thermal expansion and gas generation.

To incorporate this effect, a new state variable named "melting factor" has been introduced. The melting factor is a position-dependent property of the bed, defined as the amount of iron-containing ore that is melted during the sintering process. The

\footnotetext{
* Technical contribution to the $44^{\text {th }}$ Ironmaking and Raw Materials Seminar, $15^{\text {rd }}$ Brazilian Symposium on Iron Ore and $2^{\text {nd }}$ Brazilian Symposium on Agglomeration of Iron Ore, September $15^{\text {th }}$ to $18^{\text {th }}$, 2014, Belo Horizonte, MG, Brazil.
} 
melting factor summarizes the history of a point in the bed above the melting point, and it is therefore related to the degree of sintering. Slump, or vertical bed shrinkage at a point, is obtained by integrating the melting factor over the height of bed above the point.

To model the shrinkage of the computation domain associated with the sinter bed, a domain modification technique that allows a consistent modification of the bed height along the sinter bed is used.

Figure 4 shows an example of bed shrinkage during sintering.

The void fraction of the bed is interpolated from a known initial and estimated final value by calculating the change in the total free space within the bed. The change is a result of reactions, the melting of ore, and the associated shrinking of the bed and water condensation.

\subsection{Off-gas Recirculation}

Calculation of off-gas recirculation is possible. The off-gas recirculation system (Figure 5) takes advantage of the fact that only part of the oxygen in the ambient air is consumed for coke combustion. Therefore, part of the off-gas stream may be recycled via a special hood, enriched with ambient air to an oxygen content of about 13-15\%, and used as intake process air. This reduces off-gas volumes by about 40$50 \%$ without adversely affecting the sintering process. Using this model, heat recovery from other gas sources like sinter cooler can be calculated.

\subsection{Hearth Layer}

Sinter of a specific intermediate grain size is screened out and recirculated to the sinter machine, where it serves as a hearth layer, protecting the grate bars of the pallet cars against heat during the sintering process. This hearth layer is also taken into account in the simulation, and it can be configured via the configuration file.

\subsection{Chemical reactions}

Many kinetic reactions are involved in the sinter process. The most important reaction probably is the combustion of coke that produces the necessary heat to melt and agglomerate the ore. Thermal decomposition of ore components is interpreted as a chemical reaction as well, and several gaseous reactions and the Boudouard reaction are taken into account. As a result, we deal with homogeneous and heterogeneous reactions, where homogeneous reactions are usually modeled by Arrhenius-type models.

- Thermal decomposition of carbonates like $\mathrm{CaCO}_{3}, \mathrm{MgCO}_{3}, \mathrm{FeCO}_{3} \mathrm{MnCO}_{3}$ )

- Coke combustion

- Calcination of limestone

- Reactions of $\mathrm{CaO}$ and $\mathrm{Ca}(\mathrm{OH})_{2}$

- Iron ore reduction and oxidation

- Char gasification

- Homogeneous and heterogeneous CO oxidation

- Boudouard reaction

- Oxygen hydrogen reaction

- Drying and wetting of limestone

* Technical contribution to the 44 ${ }^{\text {th }}$ Ironmaking and Raw Materials Seminar, $15^{\text {rd }}$ Brazilian Symposium on Iron Ore and $2^{\text {nd }}$ Brazilian Symposium on Agglomeration of Iron Ore, September $15^{\text {th }}$ to $18^{\text {th }}$, 2014, Belo Horizonte, MG, Brazil. 


\section{RESULTS}

The following 2-D figures show different results:

Temperature of solids

Figure 6 shows the temperature of the solids.

Concentration of $\mathrm{CaCO}_{3}$

Figure 7 shows the concentration of $\mathrm{CaCO}_{3}$ in the solids.

Concentration of $\mathrm{CaO}$

Figure 8 shows the concentration of $\mathrm{CaO}$ in the solids.

Concentration of $\mathrm{H}_{2} \mathrm{O}$ liquid

Figure 9 shows the concentration of liquid $\mathrm{H}_{2} \mathrm{O}$ in the solids.

Suction pressure

Figure 10 shows the suction pressure

\subsection{Graphical User Interface}

All these graphs can be visualized on the screen via graphical user interface, which gives a fast overview of the results. Input is also possible via the interface.

ProcessExplorer is the basic HMl client application for Siemens VAl's Level 2 Automation systems (e.g. iron, steel processing, SIMETAL). Because it is based on a user access control concept stored inside a database, the logon procedure can be simulated with a simple $\mathrm{xml}$ file.

Figure 11 shows the typical main page of the process explorer.

Figure 12 shows an example of the user interface.

An additional advantage of using the interface is that every physical and chemical parameter can be highlighted on the screen at each and every point of the 2-D display.

\subsection{Method and Detail for Mathematic Solution}

The model solves 27 nonlinear, coupled partial differential equations for gas temperature, solid temperature, pressure, bulk density and transport equation for every specific material.

Approximately 15,000 variables are used for the calculation.

Prerequisites for software installation:

The following is a good configuration for a simulation machine:

- CPU: Intel i7 3GHz+

- Memory: minimum 4GB, DDR3 $1333 \mathrm{MHz}$ or faster

- No special requirements on IO subsystem or GPU

As such, a normal notebook would suffice.

\section{RESULTS AND DISCUSSION}

A 2-D sintering model was presented to predict the burn through of the sinter raw mix at the sintering machine. The model is based on physical and chemical reactions, transport equations and phase transformations. The model predicts not only the temperature distribution but also the distribution of chemical materials, gas pressure and solids at each point on the sinter strand. The model was already used and validated to predict changes in existing sinter plants. The model is able to

\footnotetext{
* Technical contribution to the 44 Ironmaking and Raw Materials Seminar, $15^{\text {td }}$ Brazilian Symposium on Iron Ore and $2^{\text {nd }}$ Brazilian Symposium on Agglomeration of Iron Ore, September $15^{\text {th }}$ to $18^{\text {th }}$, 2014, Belo Horizonte, MG, Brazil.
} 
calculate off-gas recirculation and implications on the process when a heat recovery system is used. The sinter simulation model has the capability to simulate the actual sintering behavior and is a useful tool for fast prediction of changes in the sintering process. The model can provide information about correct material distribution, temperature distribution, gas distribution, effect of off-gas recirculation, sulfur adsorption, heat recovery and, last but not least, it helps to select the wind box design.

This tool helps the engineer to better design and understand details of the sintering process. For the sinter plant operator, it means faster reaction and better forecast of the changes to be performed. The producing company profits from the possibility to offer its staff computer training for better understanding of the sintering process.

Optimization and validation of the simulation model is ongoing for the calculation of special cases. For Siemens VAI, a next step is to connect the sinter simulation model to the Level 2 system for in situ plant calculation and prediction of future behavior of sintering.

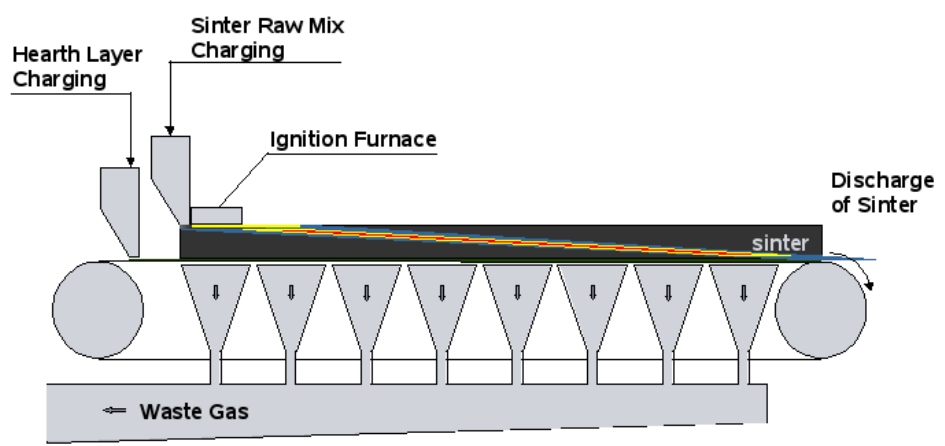

Figure 1: Schematic of a sintering machine

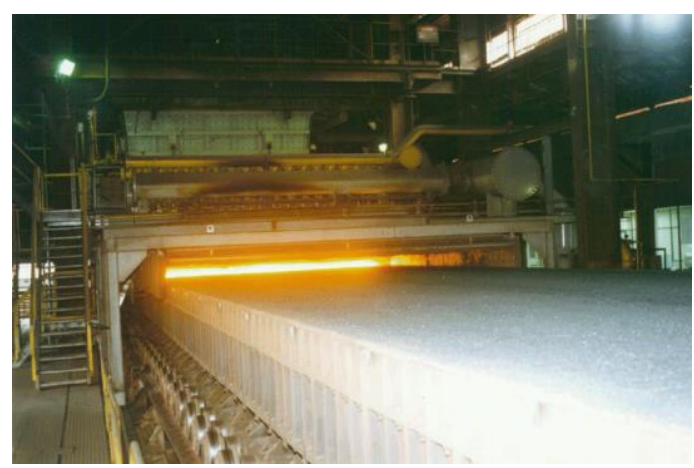

Figure 2: Photo of the ignition hood of a sinter plant.

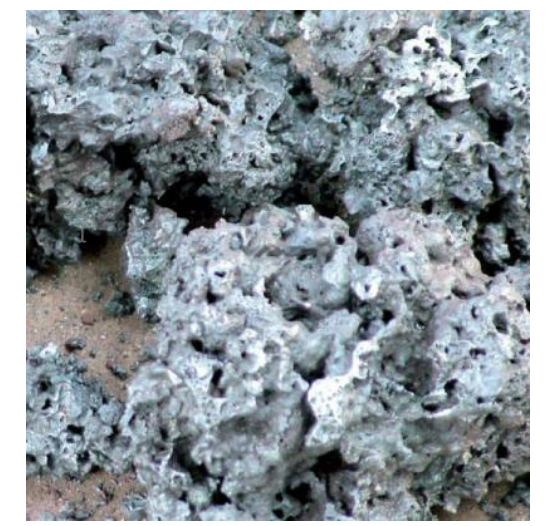

Figure 3: Photo of the final sinter product showing the clinker-like porous cellular structure.

\footnotetext{
* Technical contribution to the 44 Ironmaking and Raw Materials Seminar, $15^{\text {td }}$ Brazilian Symposium on Iron Ore and $2^{\text {nd }}$ Brazilian Symposium on Agglomeration of Iron Ore, September $15^{\text {th }}$ to $18^{\text {th }}$, 2014, Belo Horizonte, MG, Brazil.
} 


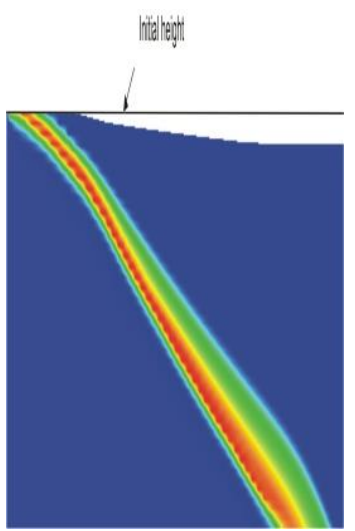

Figure 4: Bed shrinkage during the sinter process.

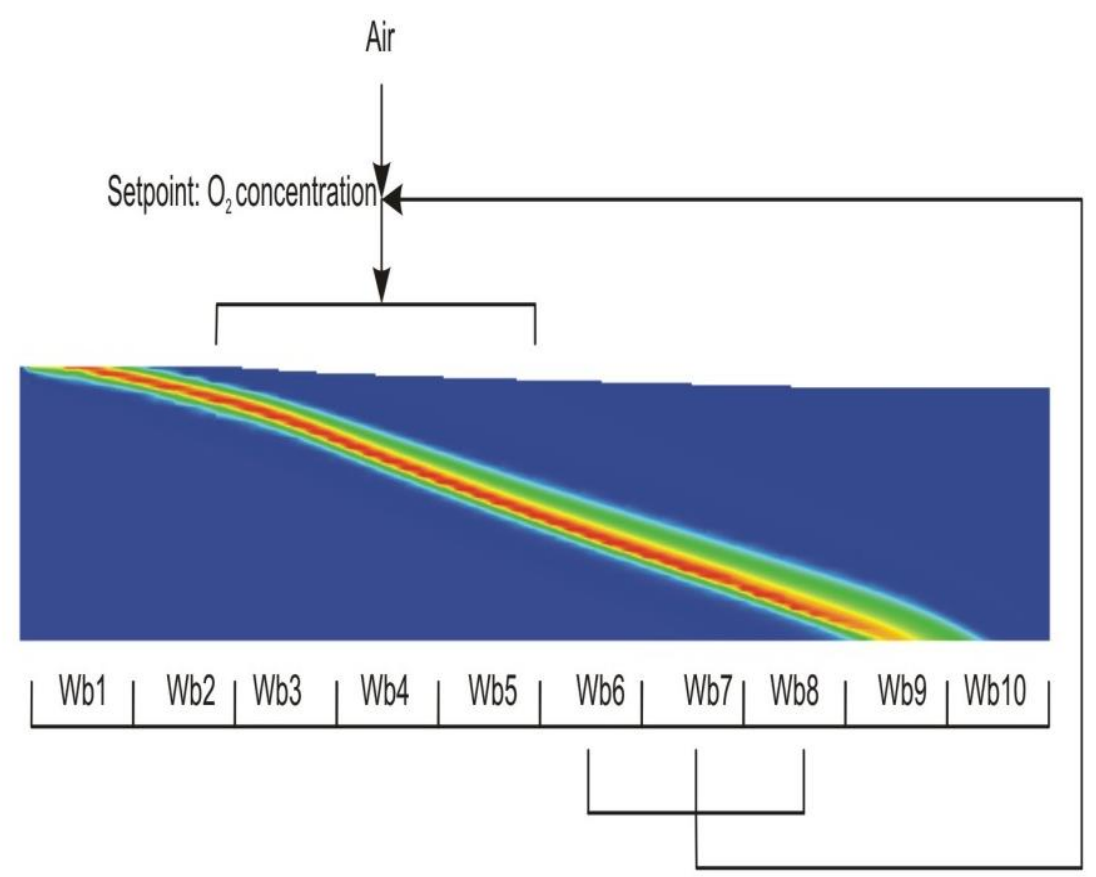

Figure 5: Off-gas recycling system. Parts of the off-gas from the bottom of the sinter bed are reused as input.

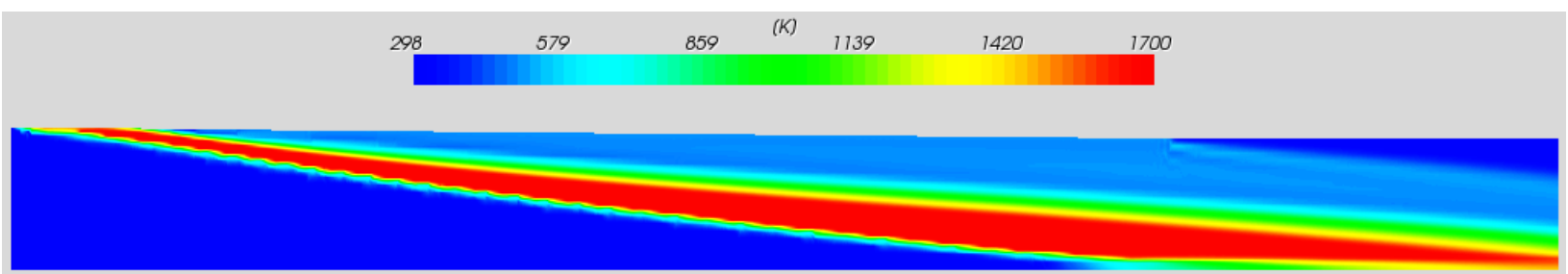

Figure 6: Temperature development across the sinter machine. The calculation also displays recirculation.

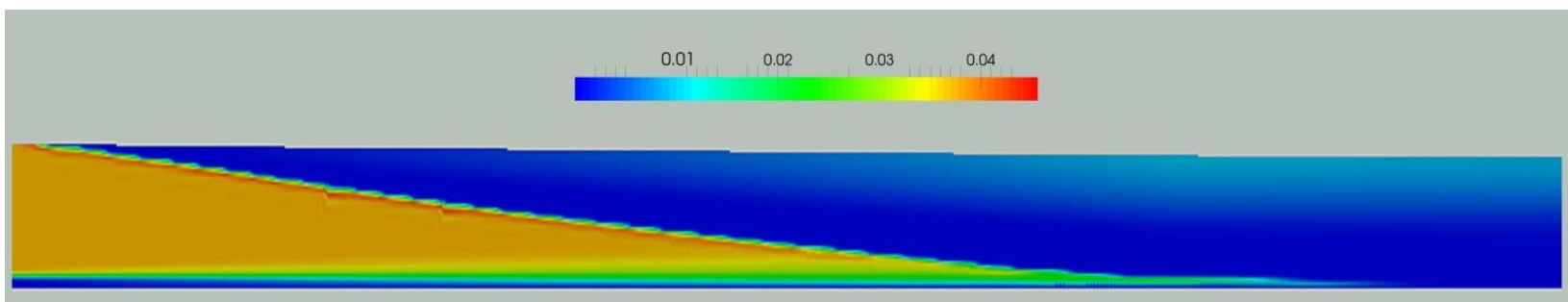

Figure 7: $\mathrm{CaCO}_{3}$ concentration in the solids.

* Technical contribution to the 44 $4^{\text {th }}$ Ironmaking and Raw Materials Seminar, $15^{\text {rd }}$ Brazilian Symposium on Iron Ore and $2^{\text {nd }}$ Brazilian Symposium on Agglomeration of Iron Ore, September $15^{\text {th }}$ to $18^{\text {th }}$, 2014, Belo Horizonte, MG, Brazil. 


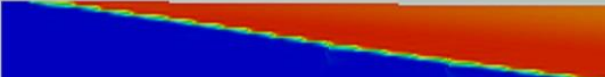

Figure 8: $\mathrm{CaO}$ concentration in the solids.

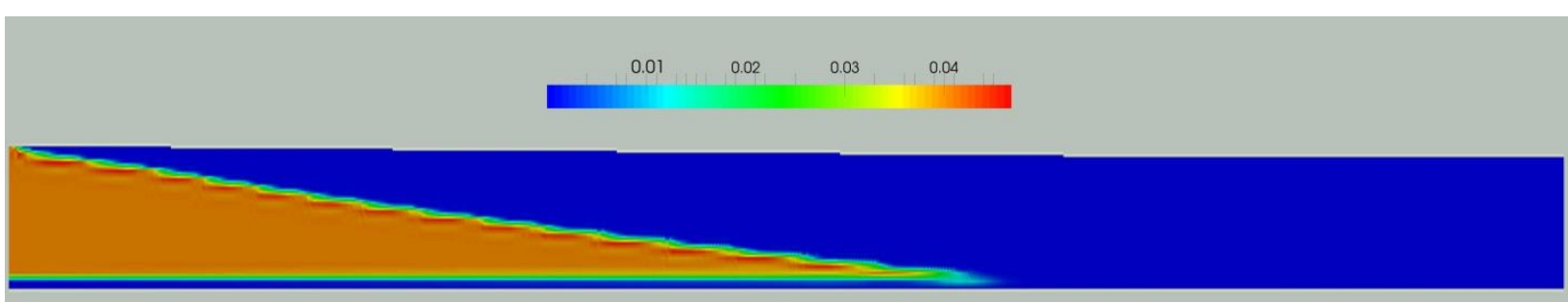

Figure 9: Liquid $\mathrm{H}_{2} \mathrm{O}$ concentration in the solids.

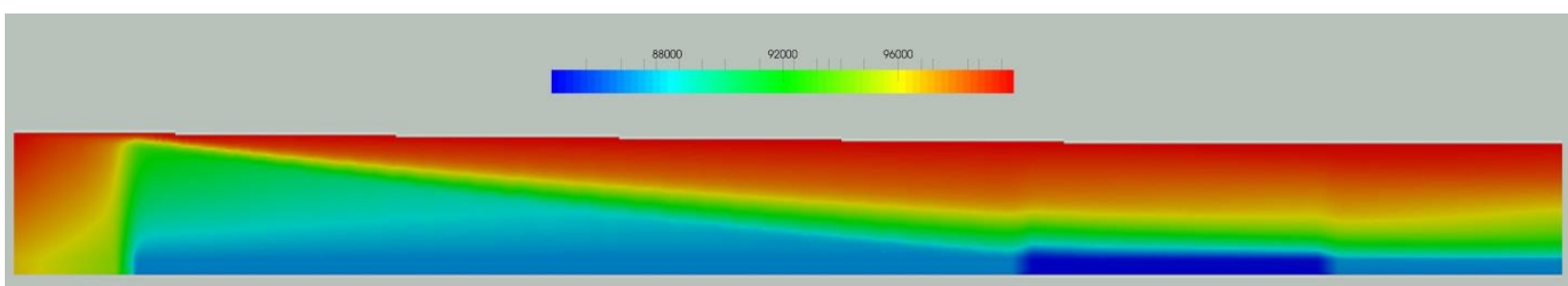

Figure 10: Suction pressure.

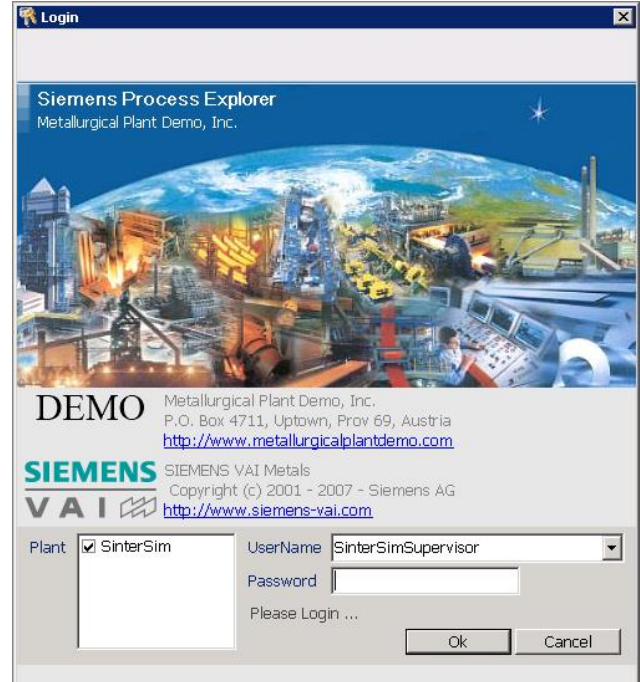

Figure 11: The typical main page of the process explorer.

* Technical contribution to the $44^{\text {th }}$ Ironmaking and Raw Materials Seminar, $15^{\text {rd }}$ Brazilian Symposium on Iron Ore and $2^{\text {nd }}$ Brazilian Symposium on Agglomeration of Iron Ore, September $15^{\text {th }}$ to $18^{\text {th }}$, 2014, Belo Horizonte, MG, Brazil. 
fire pellets in a lower layer while preventing pellets on the bed surface from overheating.

Influencing factors and simulation targets

A precisely designed induration furnace produces a uniform pellet quality over the whole cross-section of the bed. The discharge temperature of the pellets meets customer requirements with simultaneous optimization of energy consumption.

These differences in the sintering process lead to different requirements for the simulation model.

The most important factors influencing the pelletizing process are the following:

- chemical and physical properties of the green pellets

- length and distribution of process zones

- temperature of process gas in the different zones

- pressure difference over the bed and therefore transported gas volume

\subsection{The Model}

The pelletizing simulation model simulates all solid and gaseous flows in an induration machine with a traveling grate. The goal is to calculate all temperatures of the solids and gases along the pellet bed. The bed itself is divided into any number of cells. The gas flow inside the bed is simulated in three dimensions, and the solid flow in one dimension. The solids can be classified in up to seven freely selectable particle size classes, and eighteen chemical species are implemented. The gas phase consists of six species.

The machine is structured in hoods, wind boxes and collectors that are connected by ducts. A machine can be freely configured, so all conceivable plant configurations and sizes for traveling grate plants can be reproduced.

All mentioned factors influencing the process are implemented in the simulation tool either as input values (e.g. chemical composition of raw materials), boundary conditions (e.g. suction pressure in a collector) or calculation results (e.g. particle temperatures).

The calculation is carried out via CFD (Computational Fluid Dynamics) embedded in Microsoft Excel. The calculation time varies between six and ten minutes, depending on the selected number of particle classes, cells and wind boxes.

\subsection{Handling of the Model}

For given raw materials, the mix for the green balls can be selected. A virtual pelletfiring machine can be configured to work out the optimum geometry and distribution of zones for this raw material mix. All results are shown in special tables, but they can also be viewed in graphs.

Of course existing plants can also be simulated to optimize the process by adjusting several process parameters, such as suction pressure, temperature profile, green ball mix, etc.

To simulate the physical and chemical processes in the pellet bed as precisely as possible, many parameters (e.g. for chemical reaction kinetics) have been evaluated with a tailor-made test program using Siemens VAl's pellet pot in Leoben, Austria. Because of the large number of factors influencing the process - such as different raw materials, different mixes, etc. - some parameters have to be adjusted from case to case.

\footnotetext{
* Technical contribution to the $44^{\text {th }}$ Ironmaking and Raw Materials Seminar, $15^{\text {rd }}$ Brazilian Symposium on Iron Ore and $2^{\text {nd }}$ Brazilian Symposium on Agglomeration of Iron Ore, September $15^{\text {th }}$ to $18^{\text {th }}$, 2014, Belo Horizonte, MG, Brazil.
} 


\section{CONCLUSION AND OUTLOOK}

The pelletizing model is now able to calculate the temperatures and chemical compositions of gas and solids at any point inside the pellet bed induration furnace as well as pressures and gas properties (volume/mass flow, chemical composition, temperature) in all parts of the plant (hoods, ducts, collectors, wind boxes).

All possible configurations and dimensions of traveling grate induration machines can be reproduced. Many of the parameters for heat and mass transfer equations, but also parameters for chemical reaction kinetics, have been evaluated via pot tests.

With this tool, designing new plants is faster and more exact. Existing processes can be simulated, and the effects of changes on operational process parameters can be predicted. The optimization and validation of the simulation model for existing plants and special cases is the most important task for the near future.

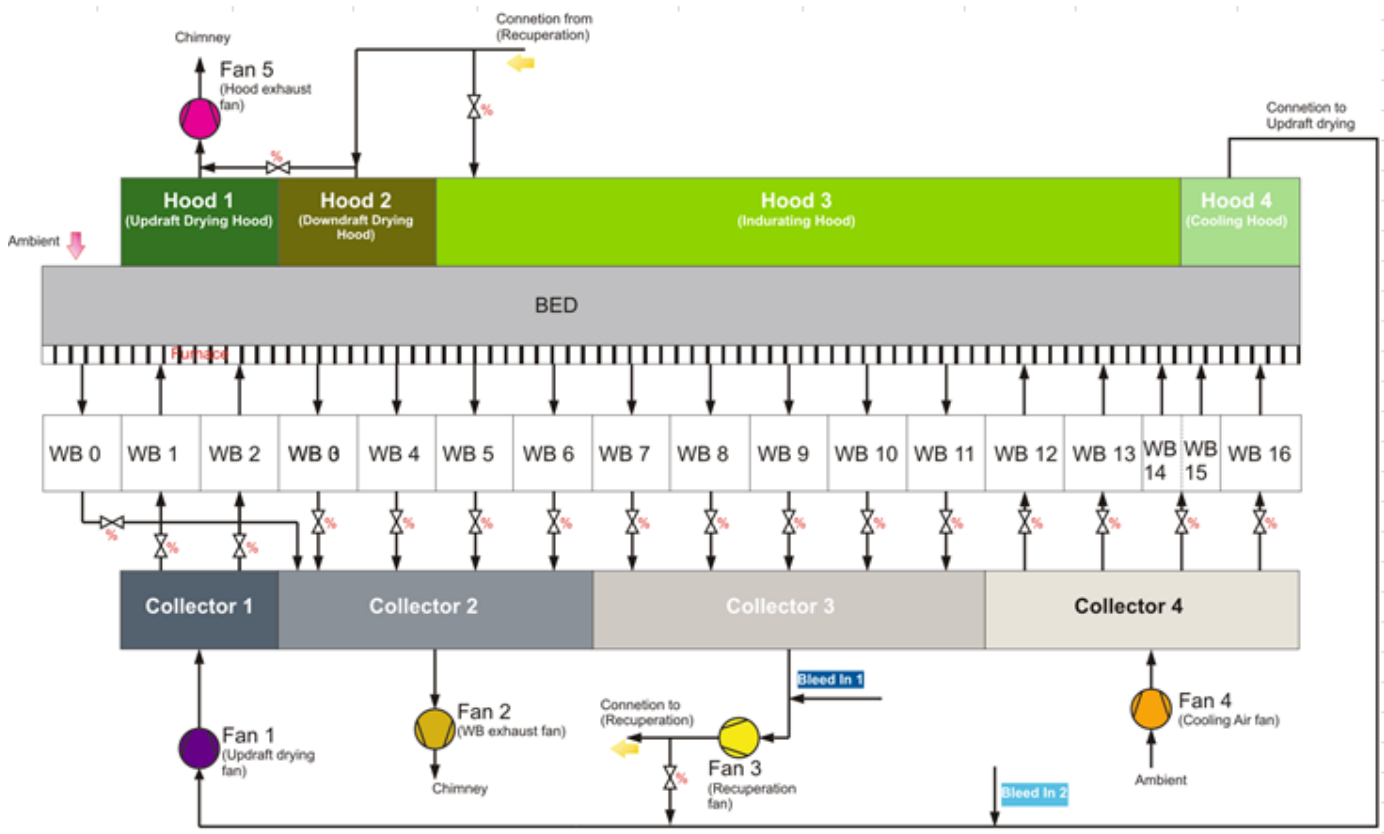

Figure 13: Schematic of a pelletizing machine as configured in the model

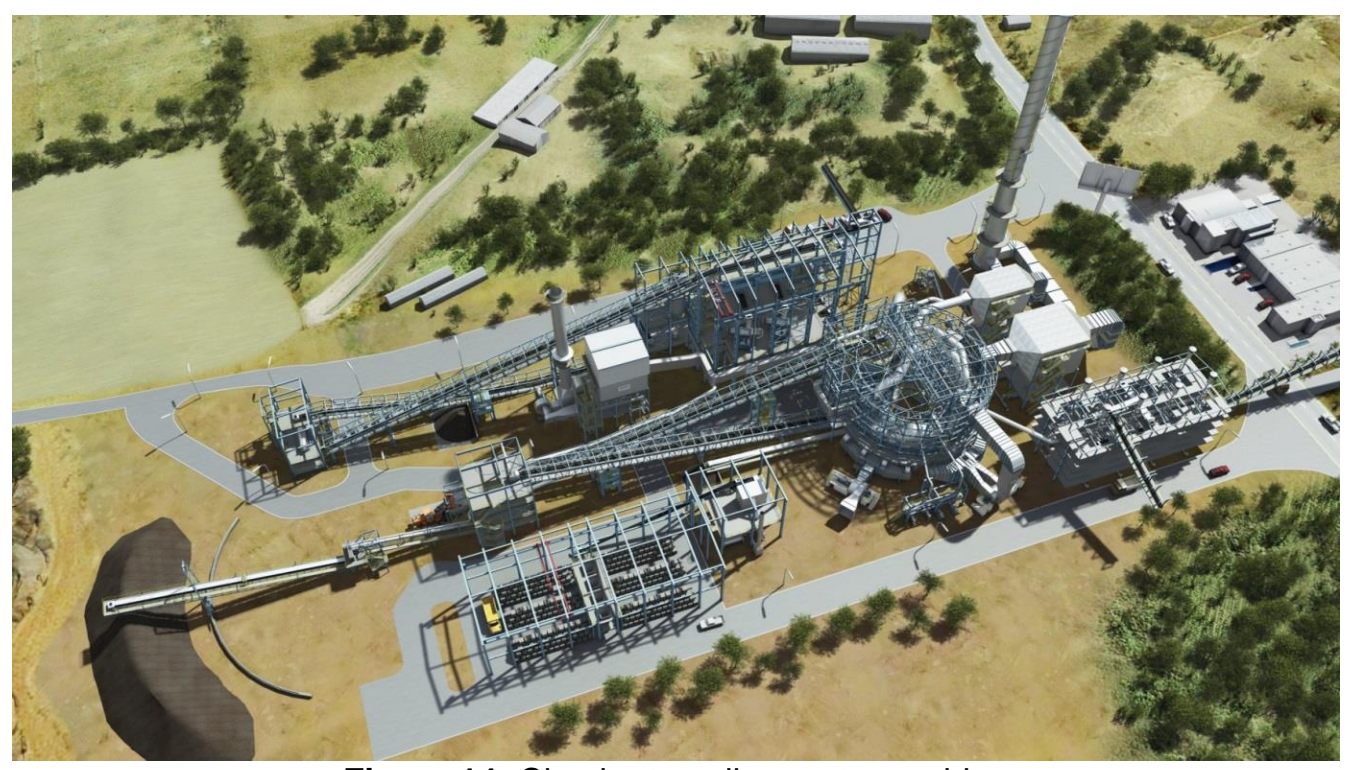

Figure 14: Circular traveling grate machine

\footnotetext{
* Technical contribution to the 44 Ironmaking and Raw Materials Seminar, $15^{\text {td }}$ Brazilian Symposium on Iron Ore and $2^{\text {nd }}$ Brazilian Symposium on Agglomeration of Iron Ore, September $15^{\text {th }}$ to $18^{\text {th }}$, 2014, Belo Horizonte, MG, Brazil.
} 


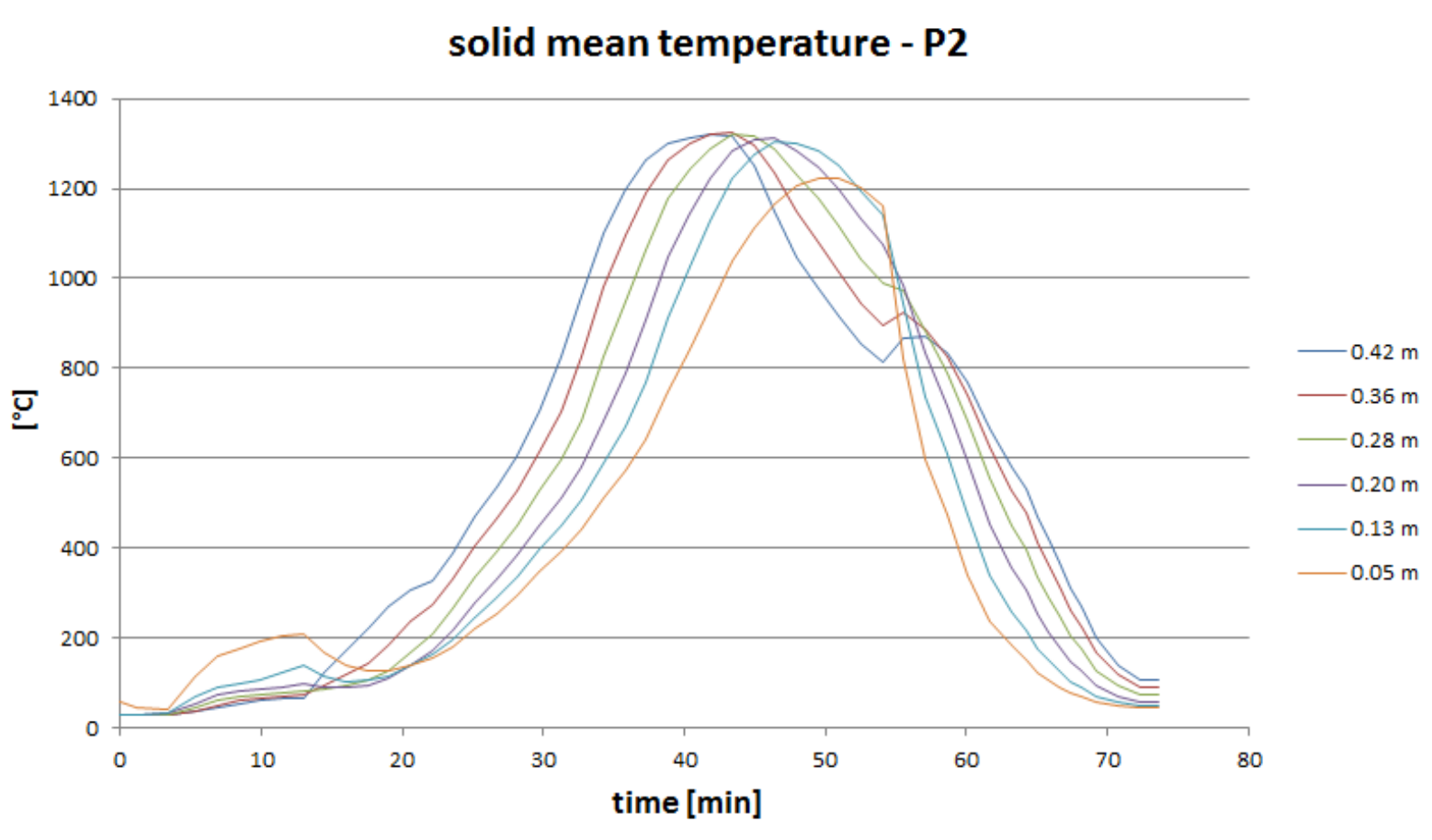

Figure 15: Sequence of solid mean temperature of particles with size 2 in different layers, from drying to cooling

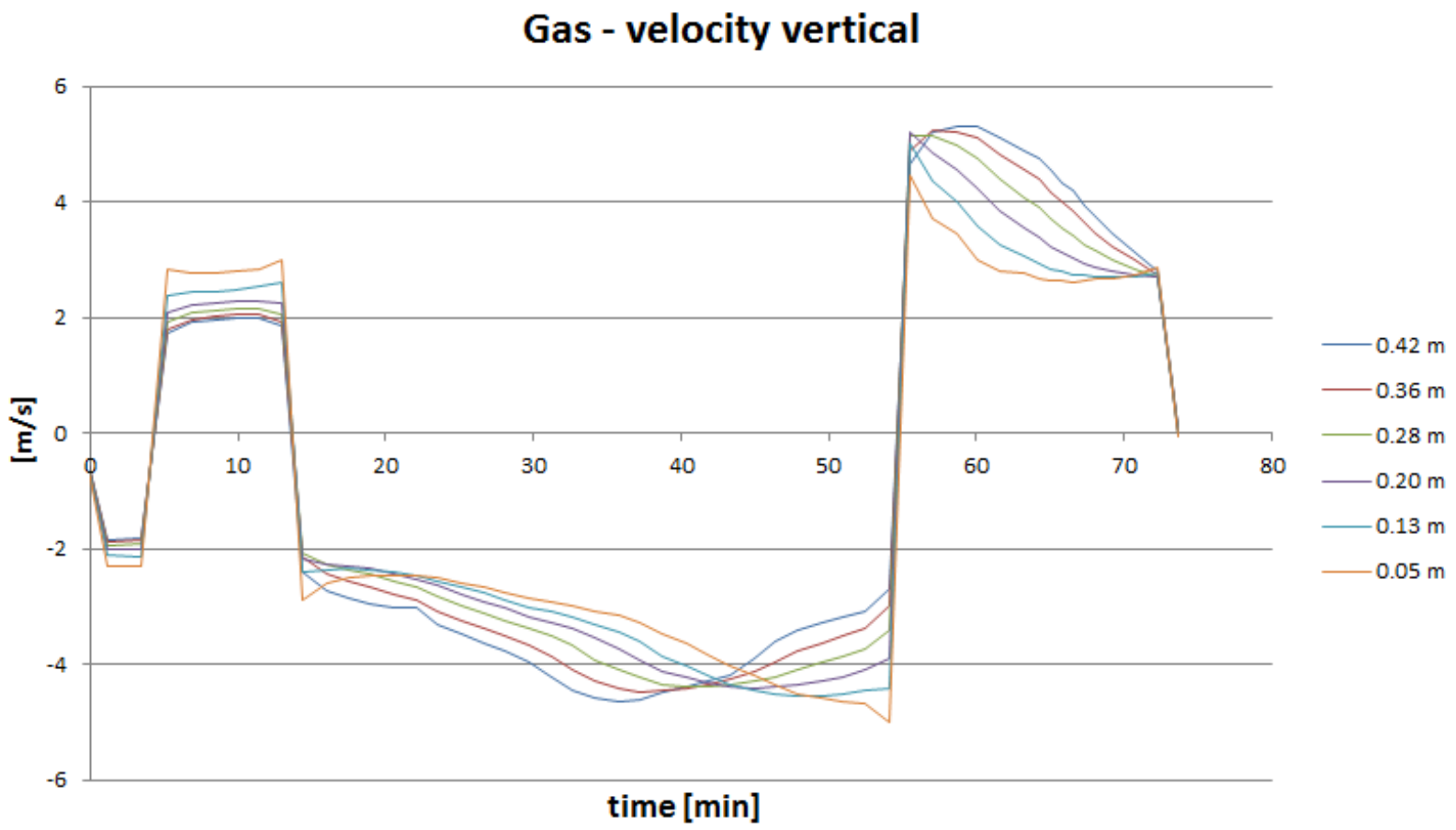

Figure 16: Sequence of vertical gas velocity in different layers, from drying to cooling

* Technical contribution to the $44^{\text {th }}$ Ironmaking and Raw Materials Seminar, $15^{\text {rd }}$ Brazilian Symposium on Iron Ore and $2^{\text {nd }}$ Brazilian Symposium on Agglomeration of Iron Ore, September $15^{\text {th }}$ to $18^{\text {th }}$, 2014, Belo Horizonte, MG, Brazil. 

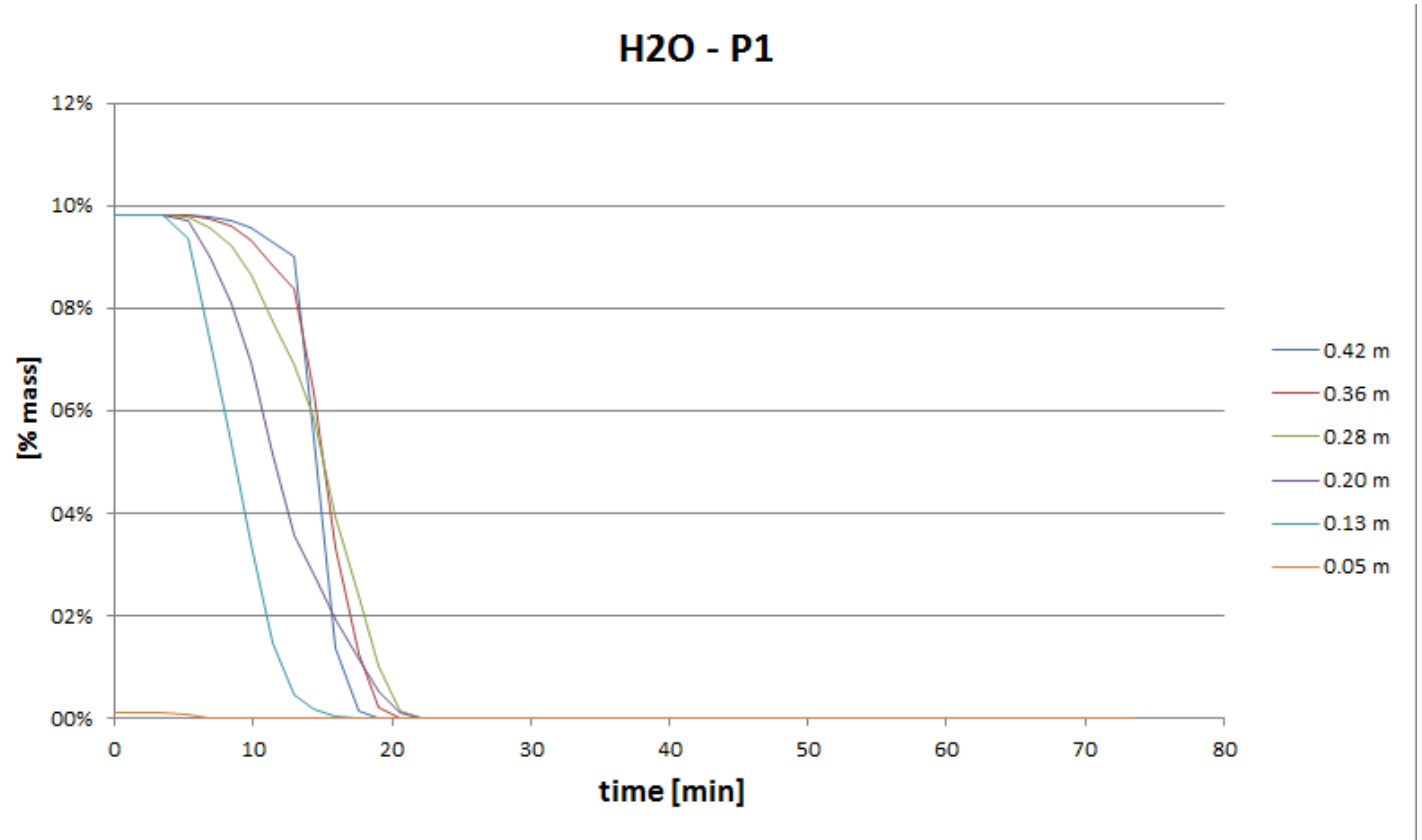

Figure 17: Content of surface water (moisture) in particle with size 1 over time

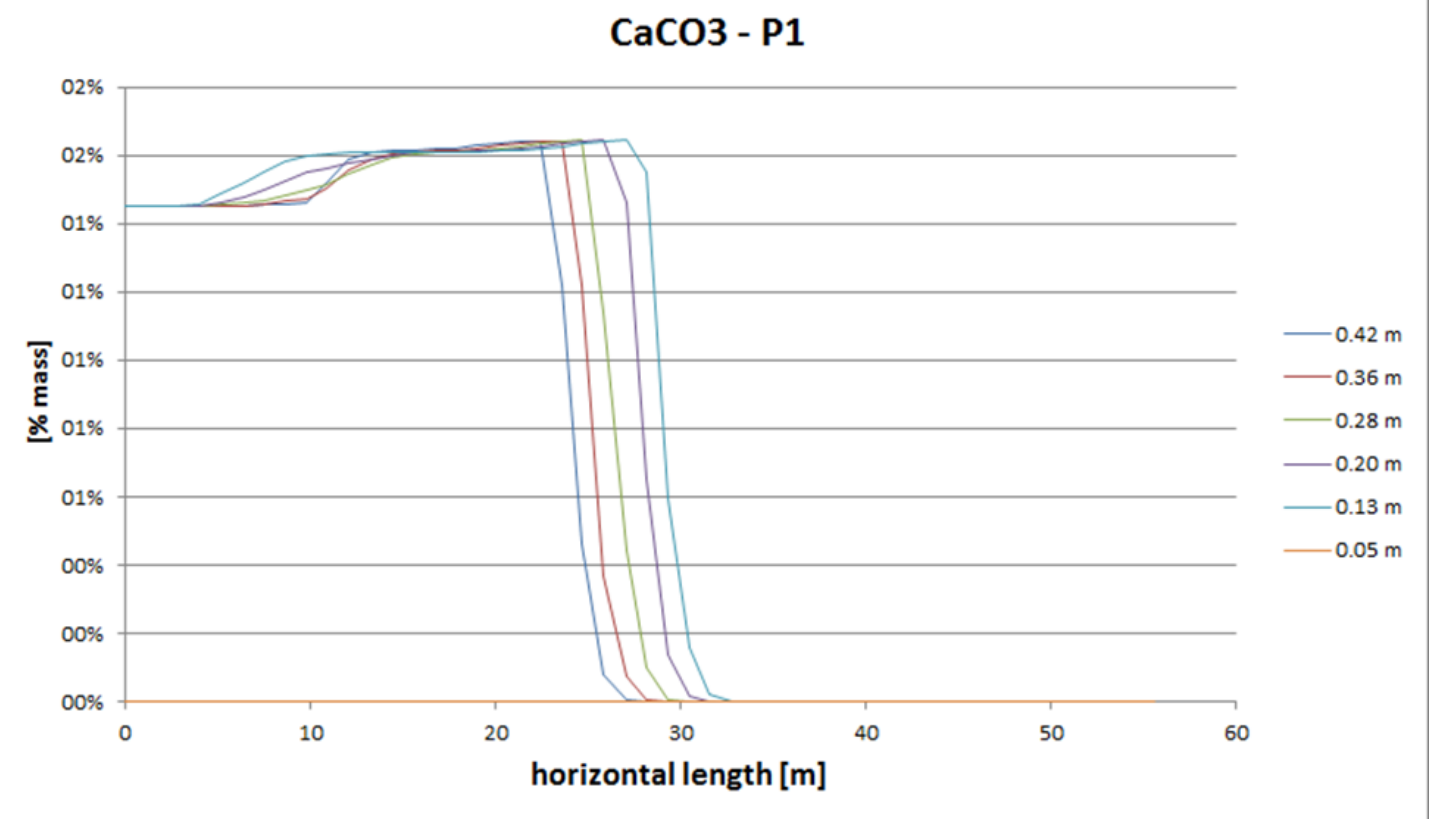

Figure 18: Content of $\mathrm{CaCO}_{3}$ in particle with size 1 over time

\section{Acknowledgement}

Mathconsult

\section{BIBLIOGRAPHY}

1 Agglomeration Processes, Wolfgang Pietsch, Wiley VcH 2002.

2 Modeling sintering Process of Iron Ore, Jose Adilson de Castro, University of Fluminene, Brazil

* Technical contribution to the 44 $4^{\text {th }}$ Ironmaking and Raw Materials Seminar, $15^{\text {rd }}$ Brazilian Symposium on Iron Ore and $2^{\text {nd }}$ Brazilian Symposium on Agglomeration of Iron Ore, September $15^{\text {th }}$ to $18^{\text {th }}$, 2014, Belo Horizonte, MG, Brazil. 